\title{
Introducing the new culture section of BJPsych Bulletin
}

\author{
David Foreman (1)
}

BJPsych Bulletin (2021) 45, 1-3, doi:10.1192/bjb.2020.128

Institute of Psychiatry, Psychology \& Neuroscience, King's College London, UK Correspondence to Dr David Foreman (david_foreman@doctors.net.uk)

First received 18 Nov 2020, accepted 18 Nov 2020

(c) The Author 2021. Published by Cambridge University Press on behalf of the Royal College of Psychiatrists. This is an Open Access article, distributed under the terms of the Creative Commons Attribution licence (http://creative commons.org/licenses/by/4.0/), which permits unrestricted re-use, distribution, and reproduction in any medium, provided the original work is properly cited.
Summary This editorial launches the new culture section in the journal. Without any unchallengeable definition of 'culture', potential contributors may consider submissions under four headings: the arts and humanities relating to practice: regulatory culture; becoming a cultured practitioner; and psychiatry's cultural context. A new article type, 'Cultural reflections', has been created, and submissions may reflect any appropriate methodology, including those from the arts. Peer review (from methodologies outside psychiatry if appropriate) will assure quality. Our objectives are to establish BJPsych Bulletin as the 'journal of record' for cultural studies relevant to psychiatric service delivery and demonstrate equivalent quality between them and scientific studies.

Keywords Psychiatry; culture; mental health; patient services.
The 'mission statement' of BJPsych Bulletin appears at the top of its Instructions for authors. It reads, 'BJPsych Bulletin prioritises research, opinion and informed reflection on the state of psychiatry, management of psychiatric services, and education and training in psychiatry'.

We try to provide what psychiatrists need to practise well. With our daily professional lives governed by scientific evidence and policy delivery, the utility of audits, guidance reviews, clinical recommendations and service-related research is obvious. However, we believe that psychiatrists also need excellent cultural understanding and culturally informed practice to deliver what our patients need from us. We have therefore created a new Cultural Section, with an associated article type, 'Cultural reflections', to allow submission of articles that do not fit the currently available Journal frameworks.

\section{What do we mean by culture?}

Like baldness or serious professional misconduct, culture is something we have little trouble recognising but great difficulty defining. Jahoda observed that the definitions of culture commonly used in psychological science are mutually incompatible, not amenable to empirical testing and suggests that we define it by usage rather than semantically. ${ }^{1}$ As editors of the journal, if someone wishes to submit something they consider 'cultural', we recommend that they think in terms of four headings: the arts and humanities concerning practice; regulatory culture; the cultured practitioner; and the cultural context within which psychiatry operates.

\section{The arts and humanities concerning psychiatric practice}

The arts and humanities are what we usually think of when 'culture' is discussed. However, while a vibrant psychiatric literature on these topics continues, a historical perspective suggests that mutual engagement and understanding between these worlds has declined. The famous painting of Pinel unchaining the inmates of the Salpêtrière, painted in 1895, illustrates not a consequence of the French Revolution but the benefits of an empirical psychiatry based on observation that prioritises patient benefit without presuming prior theory. ${ }^{2,3}$ This active, empirical approach still characterises psychiatry. ${ }^{4}$ Nevertheless, psychiatrists are now represented as theorisers, more interested in investigation than benefiting our patients, ${ }^{5}$ and sometimes entirely indifferent to them.

As the humanities' awareness and understanding of psychiatrists has diminished, so has our involvement with them. The conjunction of psychiatric, surrealist and philosophical thought between the 1920s and 1960s contributed to the development of both postmodernist thinking and antipsychiatry. ${ }^{6}$ Yet, even the memory of those connections now seems lost to us, and we are invited to consider them as if they are alien to our tradition and we had never responded. ${ }^{7,8}$

To encourage a rapprochement and interchange that takes into account the progress made since the middle of last century, we will seek to publish not only cultural thinking by psychiatrists but also work by practitioners of other methodologies. It is often forgotten that the visual arts, music, poetry and literature are also methods for exploring the world, especially our subjectivities. For psychiatry, the subjectivity of our patients is part of our core business, and we are no longer so restricted by the limits of paper 
and physical printing. We therefore do not necessarily require that a submission to the culture section is in the form of a conventional academic paper, provided that it addresses a cultural issue that has an impact on psychiatric practice and meets our quality standards.

\section{Regulatory culture}

The arts and humanities are often seen as a counterpoise to excessive regulation. However, there is also regulatory culture, which operates to deliver the intentions of a regulatory regime when circumstances are indeterminate and discretion is essential. ${ }^{9}$ It can be thought of as the set of explicit or implicit attitudes and intentions expressed through norms, routine policy and everyday practice. It has become an explicit part of financial regulation, and firms are reviewed to ensure that their management structures deliver it. $^{10}$ Within the National Health Service (NHS), regulatory culture is much more variably instituted ${ }^{11}$ and an audit model may not capture many of its necessary components. ${ }^{12}$ We therefore wish to publish articles relevant to improving the regulatory culture of psychiatric care, as the level of variation found suggests an ongoing and urgent need.

\section{The cultured practitioner}

The mission of BJPsych Bulletin focuses on topics that affect what we do in our daily practice. The norms and values that our culture instils do precisely this. For example, social constructs such as masculinity and societal power gradients predict the balance between a response style of decisiveness versus accommodation. ${ }^{13}$ The concept of specifying moral principles in practical, situational terms is well-established in biomedical ethics. ${ }^{14}$ The same is needed for cultural influences, as professional practice cannot be detached from its cultural environment. ${ }^{15}$ Patient (service user) groups have begun developing this from an antipsychiatry perspective. ${ }^{16}$ We believe that practitioners need explicit accounts of how psychiatrists should express our discipline's best culture in daily practice. We will seek articles that relate the practice of psychiatrists to aspects of culture, applied to the benefit of their patients.

\section{Culture and society}

Psychiatrists are taught their discipline as applied science. However, it is also one of society's institutions, tasked with performing an essential role. The Parthenon can be described entirely in engineering and aesthetic terms, but those perspectives do not explain how the Parthenon functioned. We also need to know that it was a Greek temple to Athena, the tutelary goddess of ancient Athens. To properly understand what our discipline delivers, and why, we need to be aware of how it is situated in our culture, how it maintains itself and the drivers that shape the services it delivers. Science is but one of these, and funding not only limits policy but also follows it. We are therefore interested in publishing articles that will let us map psychiatry's 'cultural geography', for example patterns of influence with other institutions, such as the law and politics, cultural drivers of research or service prioritisation, or the role of the relationship between psychiatrists and patients in shaping our clinical culture. We believe that having a clearer account of these will enable our profession to develop and deliver more effective services.

\section{Quality assurance}

Cultural commentary from many perspectives is becoming increasingly widely distributed (e.g. medium.com; quillette. com) and, without expertise, quality can only be judged on its language and plausibility. Even 'fact-checking' may fail when, as often occurs in cultural scholarship, accuracy lies in the awareness of multiple interpretations, rather than allegiance to one. BJPsych Bulletin has two great strengths as a forum for cultural research and scholarship in psychiatry. Being open access, it has a potential reach similar to that of the online commentaries just mentioned. However, it also has a mature peer-review system. This combination gives it the potential to become the cultural journal of record' for our profession, as peer review will be applied to all the section's submissions, and articles and correspondence can be published from outside the profession. As we have seen above, at present, our cultural memory may be too short. Given the section's intended scope, psychiatrists will not be in a position to judge the quality of all potential submissions. Therefore, we plan to create a panel of reviewers covering the full range of methodologies, including the arts, to ensure that all articles will be evaluated by a respected peer in the field, as well as receiving a psychiatric review.

\section{Submitting articles}

Articles should be submitted as 'Cultural reflections'. Since the section is new, as the Culture Editor I will be pleased to discuss possible submissions at an early stage with potential authors. The purpose of such discussions is to ensure that the submission is in a form that meets the goals of the section and is suitable for forwarding for peer review.

\section{Our hope for the future}

I have argued above that psychiatry needs to engage with culture to deliver best practice. I hope that the new section will support this by helping to establish cultural studies of all kinds as being of practical value to service delivery and demonstrating that the evidential quality of these studies is comparable with the best of scientific research.

\section{About the author}

David Foreman is an affiliate senior lecturer in the Institute of Psychiatry, Psychology \& Neuroscience, King's College London, UK. He is a member of the editorial board of BJPsych Bulletin and the editor of the new culture section.

\section{Declaration of interest}




\section{References}

1 Jahoda G. Critical reflections on some recent definitions of "culture". Cult Psychol 2012; 18: 289-303.

2 Fee E, Brown TM. Freeing the insane. Am J Public Health 2006; 96: 1743.

3 Woods EA, Carlson ET. The psychiatry of Philippe Pinel. Bull Hist Med 1961; 35: 14-25.

4 Green J. Psychiatry and the arts: new interfaces? Adv Psychiatr Treat 2008; 14: 163-6.

5 Byrne P. Why psychiatrists should watch films (or What has cinema ever done for psychiatry?). Adv Psychiatr Treat 2009; 15: 286-96.

6 Khalfa J. A theory of subversion that could not also serve the cause of oppression? Interventions [Epub ahead of print] 7 Jul 2020. Available from: https://doi.org/10.1080/1369801X.2020.1784030.

7 Bracken PJ. Postmodernism and psychiatry. Curr Opin Psychiatry 2003; 16: 673-7.

8 Lewis B. Psychiatry and postmodern theory. J Med Humanit 2000; 21: 71-84.

9 Meidinger E. Regulatory culture: a theoretical outline. Law Policy 2008; 9: $355-86$
10 Burdon WM Sorour MK Institutional theory and evolution of 'a legitimate' compliance culture: the case of the UK financial service sector J Bus Ethics 2020; 162: 47-80.

11 Dixon-Woods M, Baker R, Charles K, Dawson J, Jerzembek G, Martin G, et al. Culture and behaviour in the English National Health Service: overview of lessons from a large multimethod study. BMJ Qual Saf 2014; 23 : 106-15.

12 Liberati EG, Tarrant C, Willars J, Draycott T, Winter C, Chew S, et al. How to be a very safe maternity unit: an ethnographic study. Soc $\mathrm{Sci}$ Med 2019; 223: 64-72.

13 Johnson $T$, Kulesa $P, C$, $Y$ I, Shavitt $S$. The relation between culture and response styles: evidence from 19 countries. J Cross Cult Psychol 2005; 36: $264-77$.

14 Beauchamp TL, Childress JF. Principles of Biomedical Ethics. Oxford University Press, 1994.

15 Cocks G. Psychotherapy in the Third Reich. Oxford University Press, 1985.

16 Beresford P. 'Mad', Mad studies and advancing inclusive resistance. Disabil Soc 2020; 35: 1337-42.

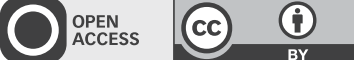

\title{
EDITORIAL
}

\section{If not now, when?}

\author{
Norman A. Poole (1)
}

BJPsych Bulletin (2021) 45, 3-4, doi:10.1192/bjb.2020.37

\author{
Department of Neuropsychiatry, \\ St George's Hospital, South West \\ London and St George's Mental Health \\ NHS Trust, UK \\ Correspondence to Dr Norman A. Poole \\ (BJPBulletin@rcpsych.ac.uk) \\ First received 24 Mar 2020, accepted \\ 24 Mar 2020 \\ (c) The Author 2020. This is an Open \\ Access article, distributed under the \\ terms of the Creative Commons \\ Attribution licence (http:// \\ creativecommons.org/licenses/by/4.0/) \\ which permits unrestricted re-use, \\ distribution, and reproduction in any \\ medium, provided the original work is \\ properly cited.
}

Summary The editor of the BJPsych Bulletin reflects on the extraordinary recent events triggered by the COVID-19 pandemic. Mental health professionals are at the front line of managing the pandemic and emergency changes should lead to a much needed refocus on what is really vital. In these unsettling times we ought to review how we manage the crisis, and its aftermath, both personally and professionally.

Keywords COVID-19; mental health services; resilience.

\section{March 2020}

My 3-year-old daughter woke this morning with a cough. Rather sweetly, she claimed she'd 'Caught hold of the cough' which she knows is making people ill. Instead of the group cycle I'd planned, I rode out on my bike alone, giving others an acceptably wide berth. Well, I say acceptably wide, but how wide is that? Two metres or more? Should I even have been out exercising? Is it a cold or COVID? How worried should I be? Pedalling into a cold northerly squall, it suddenly dawned on me: 'I'm scared'. Not so much for myself although perhaps I'm not yet willing to admit that - but for my daughter, my family, friends, their families, colleagues and, of course, our patients. We are taught that insight in psychosis is impaired, but I've often found anxiety to be less well recognised by patients, and me it turns out, than the textbooks tell us. ${ }^{1}$ It was an unsettling discovery because at that moment I also realised how powerless I am.

The neuropsychiatry team at St George's where I work had spent the previous week switching to remote clinics, mainly from home, but also seeing neurology in-patients at St George's Hospital. We learned that the liaison psychiatry service, led by the unflappable Marcus Hughes, had split 